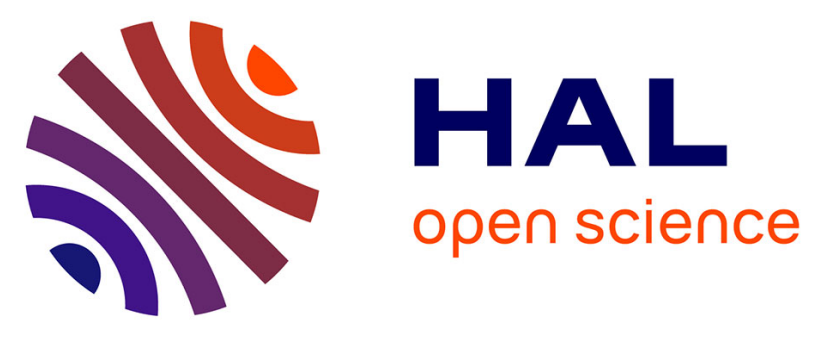

\title{
Test Rig for Applied Experimental Investigations of the Thermal Contact Resistance at the Blade-Rotor-Connection in a Steam Turbine
}

Dennis Toebben, Xavier E R de Graaf, Piotr Luczynski, Manfred Wirsum, Wolfgang Mohr, Klaus Helbig

\section{To cite this version:}

Dennis Toebben, Xavier E R de Graaf, Piotr Luczynski, Manfred Wirsum, Wolfgang Mohr, et al.. Test Rig for Applied Experimental Investigations of the Thermal Contact Resistance at the BladeRotor-Connection in a Steam Turbine. 17th International Symposium on Transport Phenomena and Dynamics of Rotating Machinery (ISROMAC2017), Dec 2017, Maui, United States. hal-02392303

\section{HAL Id: hal-02392303 https://hal.science/hal-02392303}

Submitted on 3 Dec 2019

HAL is a multi-disciplinary open access archive for the deposit and dissemination of scientific research documents, whether they are published or not. The documents may come from teaching and research institutions in France or abroad, or from public or private research centers.
L'archive ouverte pluridisciplinaire HAL, est destinée au dépôt et à la diffusion de documents scientifiques de niveau recherche, publiés ou non, émanant des établissements d'enseignement et de recherche français ou étrangers, des laboratoires publics ou privés. 


\title{
Test Rig for Applied Experimental Investigations of the Thermal Contact Resistance at the Blade-Rotor-Connection in a Steam Turbine
}

\author{
Dennis Toebben ${ }^{1 *}$, Xavier E. R. de Graaf ${ }^{1}$, Piotr Luczynski ${ }^{1}$, Manfred Wirsum ${ }^{1}$, Wolfgang Mohr ${ }^{2}$, Klaus \\ Helbig3
}

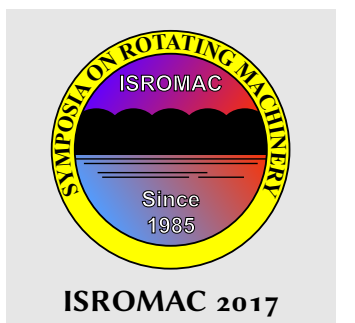

International

Symposium on

Transport Phenomena and

Dynamics of Rotating Machinery

Maui, Hawaii

December 16-21, 2017

\section{INTRODUCTION}

Steam turbines in conventional power plants are increasingly strained due to the growing demand of flexible operation. Especially frequent and fast start-up sequences lead to high thermal stress within the thick-walled components like the rotor and the casing. The temperature gradients within the solid structures which are influenced by the heat transfer coefficients at the surfaces are responsible for these high thermal stresses. Before the steam turbine is synchronized with the grid, the heavy components need to be pre-warmed. In a conventional operation superheated steam is used for heating up the steam turbine. Other approaches use hot air, for example to keep the turbine warm or to pre-warm it. In such a operation, the main heat transfer between the main flow and the structure arises at the surfaces of the blades and vanes [1]. The heat, being conducted to the rotor and the casing, has to pass the contact surfaces between the blade and rotor respectively the vane and the casing. These contact surfaces constitute a kind of bottle-neck for the heat transport which affects the temperature gradients and consequently the thermal stress.

A recent study [2] show that the contact conductance has a significant influence on the stress amplitude within the steam turbine rotor. A few experimental and analytical approaches for the determination of the thermal contact re- sistance (TCR) are known from literature. Fenech, Rohsenow, Mikic, and Yovanovich are pioneers in research on TCRtopics ([3], [4], [5]). The first investigations were conducted based on research on spacecraft and other space vehicles. A basis for further analytical approaches provide Cooper et al. [6]. They developed a calculation model for conforming (nominally flat) rough surfaces. A detailed overview on the research done on this field from 1965 to 2005 is made by Madhusudana [7]. The latest summary regarding TCR was released in 2014 in the second edition of the book thermal contact conductance written by [8]. Ustinov et al. ([9] \& [10]) developed a new model for calculating the real contact area. The experimental values provide the dependence of the TCR on roughness, material structure and the contact pressure. The results offer an explanation for the large discrepancies that exist between the data of several authors. Burghold et al. [11] introduce a method to measure contact heat transfer coefficients by means of transient temperature measurements. In these transient measurements an oscillation was observed from which a hysteresis effect arose.

In the present paper a method for applied experimental investigations of the TCR at the blade-rotor-connection in a steam turbine is presented. In the first part of the paper, the test rig and the numerical specimen model is introduced with a detailed explanation of the boundary conditions. Subsequently, the measurement values are discussed in an un- 
certainty analysis. The third part shows first measurements of the temperature at 26 different measurement positions within the specimen by variation of the contact pressure and the heat flux. In the last part of the present paper the TCR is determined by use of the numerical model and based on the experimental results.

\section{NOMENCLATURE}

Symbols
$A$
$G r$
$\operatorname{Ra}$
$P r$
$p$
$g$
$n$
$\dot{Q}$
$T$
$\bar{T}$

Area
Grashof-number
Rayleigh-number
Prandtl-number
Pressure
Gravity
Rotational speed
Heat flux
Temperature
Average temperature

\section{Greek}

$\alpha$
$\beta$
$\delta$
$\Delta$
$\eta$
$\lambda$
$\vartheta$

$\begin{array}{ll}\begin{array}{l}\text { Abbreviations } \\ \text { atm }\end{array} & \text { Atmospheric ambient pressure } \\ \text { AP } & \text { Air pocket } \\ \text { BRC } & \text { Blade-Rotor-Connection } \\ \text { CHT } & \text { Conjugate Heat Transfer } \\ \text { CI } & \text { Contact interface } \\ \text { FEM } & \text { Finite Element Method } \\ \text { rel. err. } & \text { Relative error } \\ \text { TCR } & \text { Thermal Contact Resistance } \\ \text { T1 - T26 } & \text { Thermocouples } \\ \text { U95.4 } & \text { Interval with 95.4 \% level of confidence } \\ \text { vac } & \text { Evacuated ambient pressure } \\ \text { Subscripts } & \\ \text { o } & \text { Reference } \\ \text { c } & \text { Contact } \\ \text { cool } & \text { Cooling } \\ \text { H } & \text { Heating plane (average of T1 \& T4) } \\ \text { HC } & \text { Heating cartridge } \\ \text { R } & \text { Reference thermocouple for calibration }\end{array}$

analyze the influence of the rotational speed (i.e. contact pressure), the ambient pressure and the contact surface properties (e.g. roughness, oxidation layer, lubricant). Furthermore, the radiation influence via the air pockets, which are located between the contact surfaces can be investigated. The TCR is calculated according to Eq. (1) in which $\dot{Q}_{c}$ is the heat flux through the contact surface $A_{c}$ and $\Delta T_{c}$ is the temperature difference between the area averaged temperatures of both surfaces which are in contact.

$$
T C R=\frac{\Delta T_{c} A_{c}}{\dot{Q}_{c}}=\frac{1}{\alpha_{c}}
$$

Figures 1 and 2 illustrate the single components of the test rig. The key component is the traction system (1) in which the specimen is installed. The traction system is located within a pressure chamber (2). By evacuating the surrounding air within this chamber, the heat losses can be minimized. In addition, the pressure chamber provides the opportunity to investigate the impact of the ambient pressure on the contact heat transfer by pressurizing. The hydraulic system (3) serves to adjust the traction force and thus the contact pressure. The peristaltic pump (4), the air cooler (5) and the tempered water tank (6) belong to the cooling system. The air cooler dissipates the heat absorbed from the specimen. A tempered water tank and the peristaltic pump ensure the reproducibility of the measurement. Component (7) is a monitored oil bath in which the reference thermocouples are located.

Figure 3 shows the installed specimens. The experimental set-up consists of two parts. A blade specimen and a rotor specimen with its blade groove are installed in this configuration . During the test, the specimens are surrounded by an additional casing faced by high temperature insulation to reduce radiation heat losses. The blade specimen is heated up by two heating cartridges at the top in a horizontal plane.

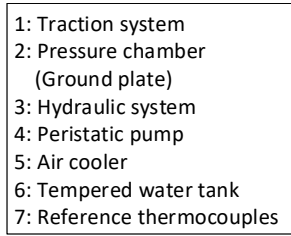

\section{TEST RIG}

Figure 1 shows the test rig, which is designed for the measurement of the thermal contact resistance (TCR) at the contact areas of a turbine blade. Different designs of blade or vane roots can be investigated. The test rig offers the possibility to

Figure 1. CAD model 
A heat flux from the top of the blade to the rotor specimen is generated by a cooling drill at the bottom of the rotor specimen, through which cooling water is pumped. The rotor specimen is fixed at the bottom. Whereas, above the heating cartridges the traction force is transmitted. The traction force is provided by a hydraulic stamp and measured by a load cell below the fixed baring.

Figure 4 illustrates the supply scheme. During the test a multitude of measurements are collected. 26 Type-N thermocouples in total are used for the measurement of the temper-

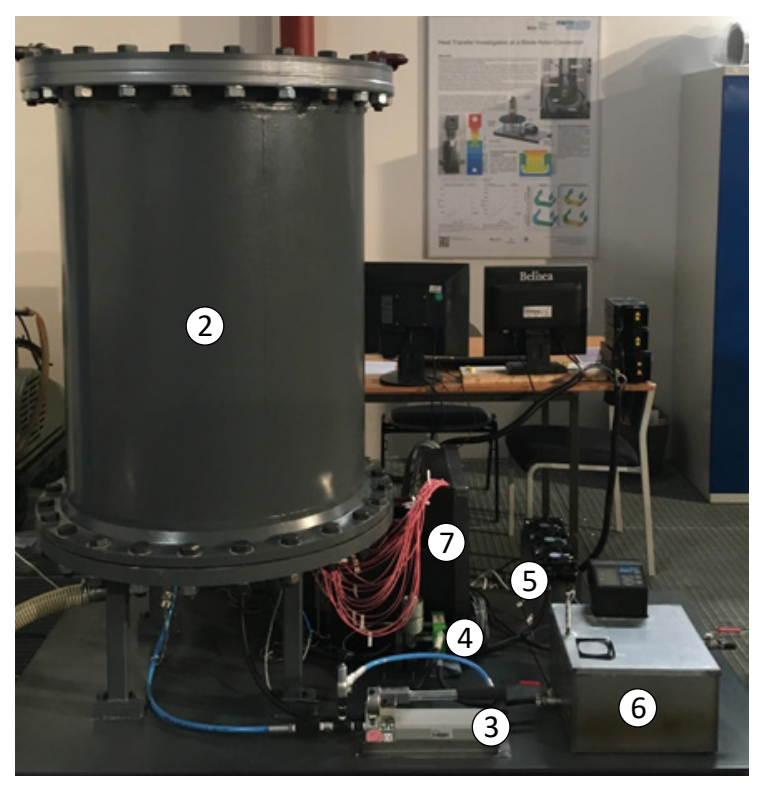

Figure 2. Test rig

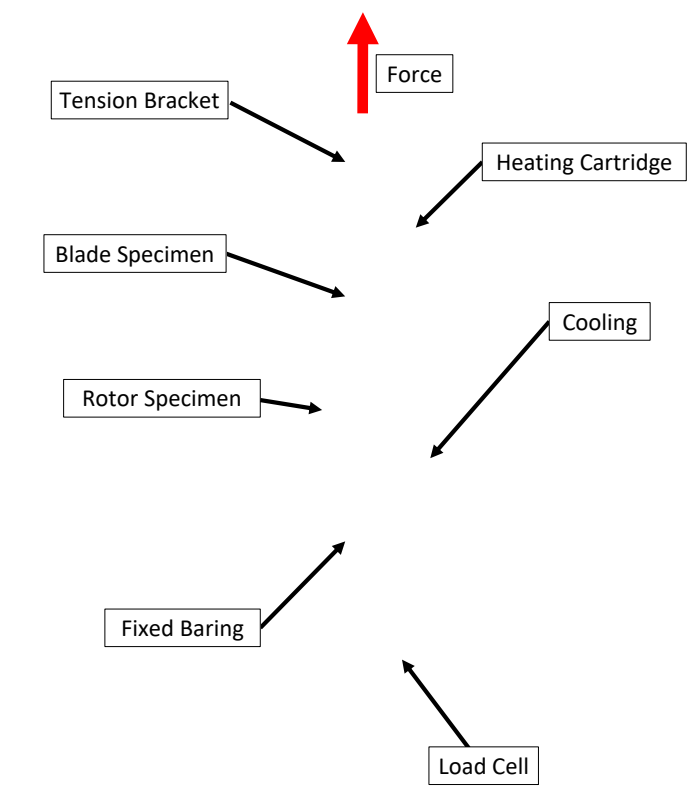

1 ature distribution inside the specimen. These measurement signals are transmitted through the pressure chamber. Each measurement signal is compensated by a reference measurement in a oil bath which is monitored by a PT-10o thermocouple. The traction force is measured by a calibrated load cell as mentioned before. To monitor the boundary conditions within the pressure chamber the temperature and the pressure is measured. The temperature of the water tank as well as the temperature of the heating cartridges are recorded to control the supply system. For a high accuracy the complete measurement chain in the final experimental set-up including the data logging system, ducts and compensation is calibrated. The measurement points are shown in Fig. 5. The upper four (pair 1) and the lower six measurement points (pair 7) are used to measure the heat input and output. Due to balancing the energy flow in this way, a higher accuracy can be achieved compared to the measurement of the power input by the heating cartridges (which is affected by heat losses through the traction rod) and the temperature difference between inlet and outlet of the cooling water. The measurement points of pair 2 to 5 are used to determine the thermal contact resistance. All other temperature measurements are used to investigate the heat transfer through the air pockets and to validate the numerical model which is shown in Fig. 6. The relevant test rig and material properties are summarized in Table 1.

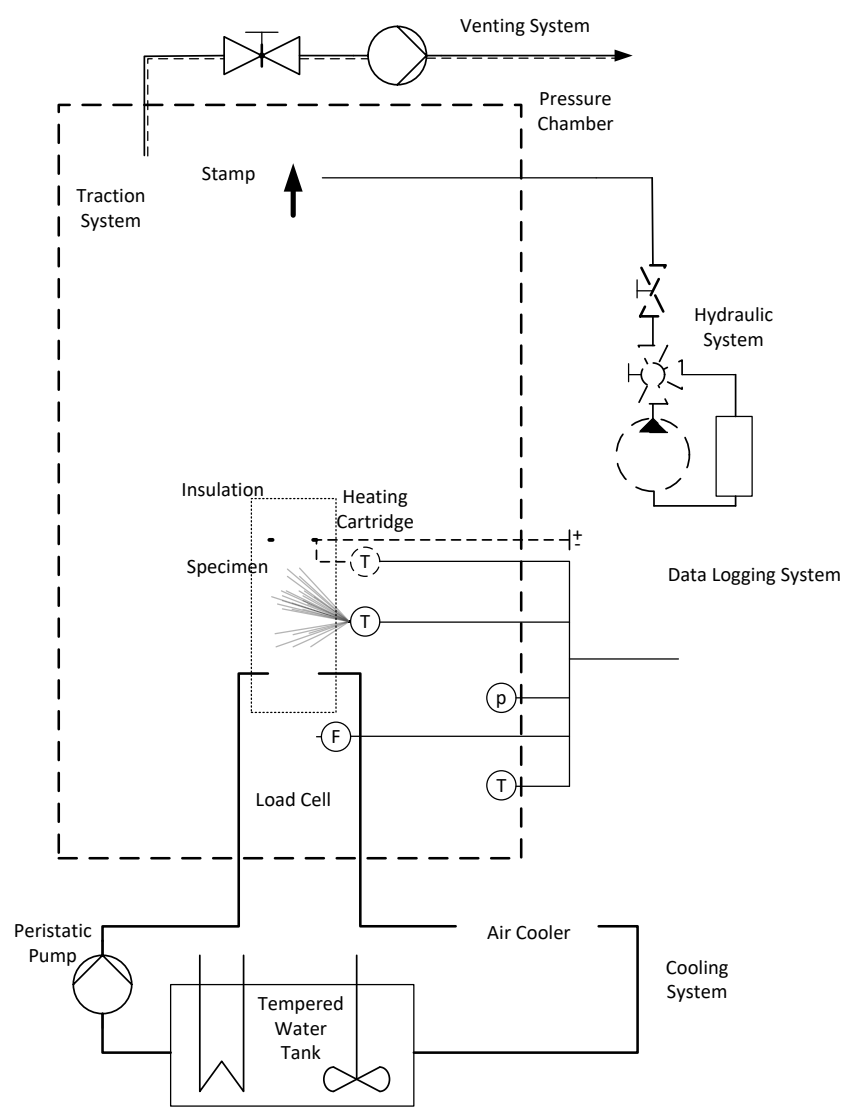

Figure 4. Supply scheme

Figure 3. Installed specimens 
Table 1. Test rig and material properties

\begin{tabular}{|l|c|}
\hline Contact pressure (max.) & $100[\mathrm{MPa}]$ \\
\hline Average temperature at CS & $100-300\left[{ }^{\circ} \mathrm{C}\right]$ \\
\hline Ambient pressure & $30-3000[\mathrm{mbar}]$ \\
\hline Heating input $($ max. $)$ & $630[\mathrm{~W}]$ \\
\hline Conductivity $\left(20-650^{\circ} \mathrm{C}\right)$ & $24-29[\mathrm{~W} / \mathrm{m} / \mathrm{K}]$ \\
\hline Surface roughness $\left(R_{z}\right)$ & $6.4[\mu \mathrm{m}]$ \\
\hline Used material & $\mathrm{X} 22 \mathrm{CrMoV} 12-1$ \\
\hline
\end{tabular}

Both the blade and the rotor specimen are made of the same material (Table 1), which is heat resistant under high load. This material is similar to the material which is used in modern high and intermediate pressure steam turbines. The geometry of the blade has been modified to enable heat input and the tensile strength. For the design of the specimen, numerical Finite Element Methods (FEM) and Conjugate Heat Transfer (CHT) calculations were used to optimize the stability, the homogeneity of temperature and the heating up time. The blade root design is straightened, however, the contact surfaces represent the original design.

\section{NUMERICAL MODEL \& ANALYSIS}

There are three reasons for building-up the numerical model of the specimen: Support in the design process, investigation of the heat transfer mechanisms between blade and rotor and in a further step the validation as well as development of a contact heat transfer correlation.

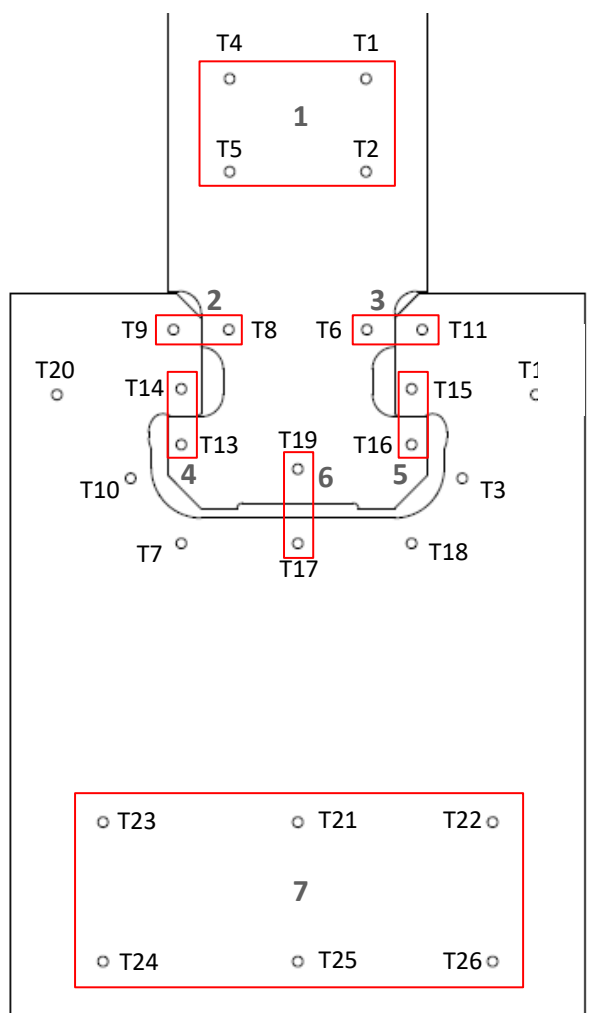

Figure 5. Measurement positions
Steam Turbine $-4 / 9$

During the design process the numerical model was used to design the required heating and cooling conditions and to secure the mechanical stability of the specimen by simulation of the mechanical and thermal induced stresses. In a next step, the geometry parameters were optimized. The width of the specimen conforms with the axial distance between two neighboring repetitive stages. The length of the rotor and the blade specimen was calculated to find an optimum regarding a uniform temperature distribution in the horizontal planes of pair 1 and pair 7 - which guarantees a minimal error in the energy balance - as well as regarding the heating up time or rather the total surface area which affects the heat losses to the ambient. Subsequently, the numerical model was used to find suitable measurement points close to the contact surface but simultaneously with a high temperature difference between opposed measurement points to minimize the relative measurement error. For that purpose, analytical approaches for the determination of the TCR from literature [6] were integrated into the numerical model.

Two different numerical models exist. A CHT model in ANSYS CFX (Fig. 6) to calculate the heat fluxes and the temperature distribution. The results of these calculations serve as an input parameter for the second model in ANSYS MECHANICAL which uses Finite Element Methods (FEM) to calculate the thermal and mechanical stresses and the resulting deformation. Two different types of meshes of the solid body are used. A tetrahedral mesh including the thermocouple holes and a hexahedral mesh without these holes. Both models use temperature-dependent material properties of the steel and data based fluid properties (IAPWS Libary). The SST turbulence model is used for the simulation of the cooling.

For the present investigations a hammer-head blade root design (Fig. 6) is used. This blade root design has four contact interfaces, two in axial direction (CI1a \& CI1b) and two in radial direction $\left(\mathrm{CI}_{2} \mathrm{a} \& \mathrm{CI} 2 \mathrm{~b}\right)$. Between the blade root and the rotor as well as between the axial $\left(\mathrm{CI}_{1}\right)$ and radial $\left(\mathrm{CI}_{2}\right)$

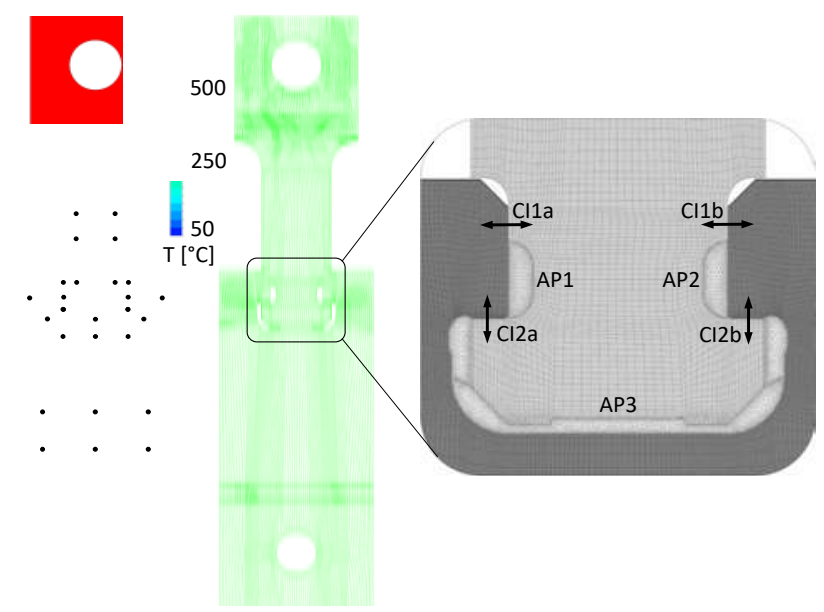

Figure 6. CHT simulation with hexahedral mesh (left), hexahedral mesh (center), contact interfaces (CI) and air pockets (AP) (right) 
contact areas air pockets can be found. Within theses air pockets heat transfer due to thermal convection, conduction and radiation occurs. For the investigation of the impact of thermal convection the Rayleigh-number $(R a)$ is calculated using Eq. (2).

$$
R a=G r \cdot P r=\frac{\beta g \rho^{2}|\Delta T| \delta^{3}}{\eta^{2}} \cdot \frac{\eta c_{p}}{\lambda}
$$

In Eq. (2) the expansion coefficient is evaluated as $\beta=1 / \bar{T}_{A P}$ and $\delta$ is the gap width of the air pocket between blade root and rotor groove. Based on the assumption of an average air temperature of $\bar{T}_{A P}=250^{\circ} \mathrm{C}$ within the air pockets and the temperature difference between the enclosed air and the average contact surface temperature of $\Delta T=50 \mathrm{~K}$ (in a conservative estimation), the Rayleigh-number is calculated to $R a=3.163$. Because of such a low Rayleigh-number it is assumed that thermal convection can be neglected as shown in [12]. For the calculation of the heat transfer by conduction and radiation through the air pockets, a separate mesh for these cavities is generated as shown in the right chart of Fig. 6. For a higher stability of the numerical simulation, the air pockets are defined as solid bodies with the transparency and conductivity of air depending on the average air properties. Figure 7 shows the influence of the thermal conduction and the heat radiation through the air pockets on the total heat transfer from blade to rotor $\left(\dot{Q}_{\text {total }}\right)$. The calculations are conducted with constant temperature at the heat source $\left(T_{H C}=500^{\circ} \mathrm{C}\right)$ and at the heat sink $\left(T_{C o o l}=30^{\circ} \mathrm{C}\right)$. With increasing TCR ( Eq. (1)) the impact of heat radiation and conduction through the air exponentially increases. With $T C R \rightarrow 0$ the heat transfer through the air pockets $\left(\dot{Q}_{A P}\right)$ related to the heat transfer through the contact interfaces $\left(\dot{Q}_{c}\right)$ is about $9 \%$ for radiation as well as conduction and about $5 \%$ for only radiation (Fig. 8). The effect of heat radiation grows with increasing average temperature level $\bar{T}_{A P}$ and also with increasing temperature difference of the surfaces in contact.

During a warm-keeping or a pre-warming process, very low rotational speeds of the turbine rotor are possible, depending on the turning engine. In this case, low centrifugal forces as well as low contact pressures occur resulting in high TCRs. Thus, the heat radiation and the conduction through the AP have to be considered.

\section{UNCERTAINTY ANALYSIS}

In order to quantify uncertainties of the measured data, the full measuring chain has to be analyzed. This analysis is conducted based on the "guide to the expression of uncertainty in measurement" [13].

The uncertainty analysis can be divided into two parts. The first part includes all 26 Type- $\mathrm{N}$ thermocouples mounted on the specimen. The upper 20 thermocouples (pairs 1-6 in Fig. 5) are calibrated in a temperature range of $100^{\circ} \mathrm{C}-500^{\circ} \mathrm{C}$. The lower 6 thermocouples (pair 7) are calibrated in a temperature range of $40^{\circ} \mathrm{C}-90^{\circ} \mathrm{C}$. In accordance to [14], the calibration is performed through a polynomial fit of 7 th degree. Con- sequently, every thermocouple has individual parameters. After the calibration, the thermocouples are compared through a reference measurement at three temperature points. This reference measurement enables to identify temperature differences between thermocouples after the calibration. The arrangement of thermocouples in groups with the lowest offset temperature between each other, enables to achieve a very low relative measurement uncertainty (Table 2). The approach to examine the relative measurement uncertainty instead of the absolute measurement uncertainty based on [13] is legitimate, due to the use of temperature differences for determination of the thermal contact resistance. $\Delta T_{R, i}$ describes the maximum temperature difference at all reference

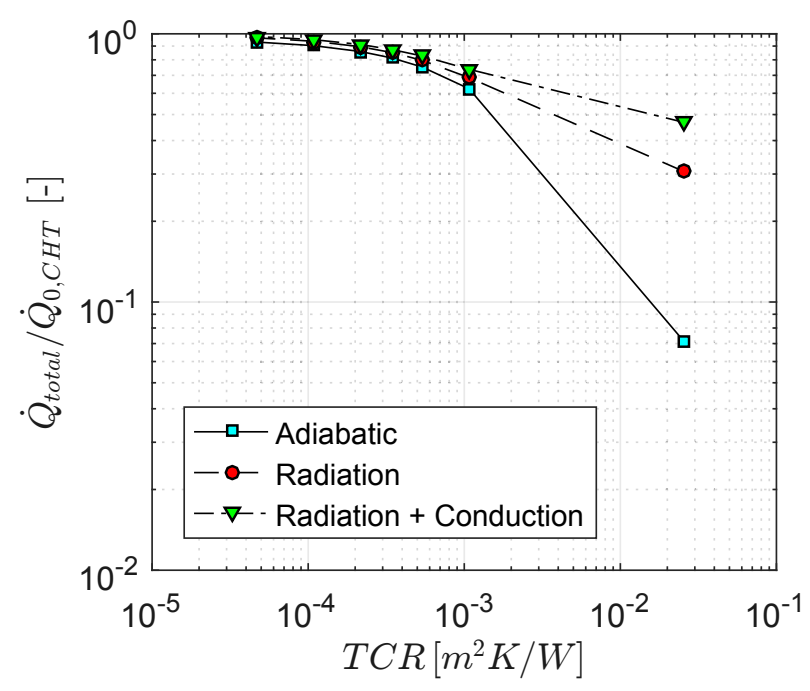

Figure 7. Total heat transfer from blade to rotor regarding different heat transfer phenomena through the air pockets $\left(\mathrm{CHT}\right.$ model $\left.T_{H C}=500^{\circ} \mathrm{C}, T_{\mathrm{Cool}}=30^{\circ} \mathrm{C}\right)$

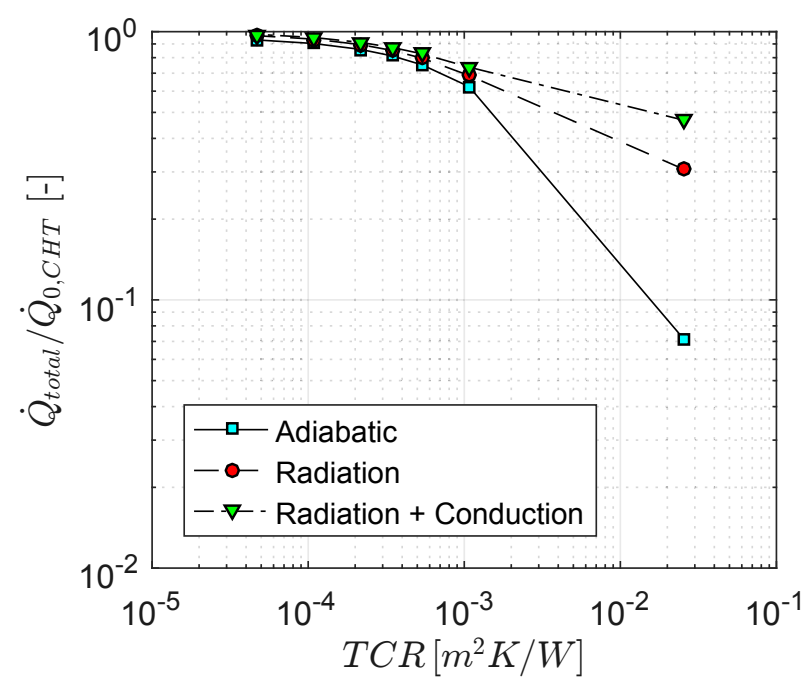

Figure 8. Heat transfer through the air pockets related to the contact heat transfer $\left(\mathrm{CHT}\right.$ model $T_{H C}=500^{\circ} \mathrm{C}$, $T_{\text {Cool }}=30^{\circ} \mathrm{C}$ ) 
measurement points of pair $i$. The term $\Delta \bar{T}_{\text {min,i }}$ indicates the minimum temperature difference within pair $i$ throughout the operating range of the test rig. So, the stated relative error $\left(\triangle T_{R, i} / \triangle \bar{T}_{\text {min,i }}\right)$ in Table 2 represents the maximum relative error of the thermocouple pairs.

Table 2. Absolute and relative error of thermocouples mounted on the specimen

\begin{tabular}{|l||c|c|c|}
\hline & $\Delta T_{R, i}[\mathrm{~K}]$ & $\Delta \bar{T}_{\min , i}[\mathrm{~K}]$ & rel. err. [\%] \\
\hline \hline Pair (1-7) & 0.515 & 88.346 & 0.583 \\
\hline Pair 2 & 0.064 & 40.935 & 0.156 \\
\hline Pair 3 & 0.089 & 42.24 & 0.211 \\
\hline Pair 4 & 0.028 & 15.708 & 0.178 \\
\hline Pair 5 & 0.094 & 17.353 & 0.542 \\
\hline Pair 6 & 0.014 & 45.01 & 0.031 \\
\hline
\end{tabular}

${ }^{*}$ Difference between pair 1 and pair 7 .

The second part of the uncertainty analysis includes every measurement equipment used to monitor the experimental test rig. This equipment is also used to reproduce certain measurement points during series of measurements. Table 3 shows that the temperature level $\left(T_{H C}\right)$ can be reproduced in a range of $4.7 \mathrm{~K}$ in maximum. The reproducibility of the tensile force has a maximal relative error of $1.01 \%$ and the PT10o has an uncertainty of $0.243 \mathrm{~K}$.

Table 3. Uncertainty analysis of remaining measurement equipment

\begin{tabular}{|l||c|c|c|}
\hline & Measurement range & U95.4 & rel. err. \\
\hline \hline PT100 $\left[{ }^{\circ} C\right]$ & $18-30$ & 0.243 & $1.35 \%$ \\
\hline$T_{H C}\left[{ }^{\circ} C\right]$ & $210-550$ & 4.664 & $2.22 \%$ \\
\hline$p[\mathrm{mbar}]$ & $30-1030$ & 0.401 & $1.34 \%$ \\
\hline$p_{c}[\mathrm{MPa}]$ & $4.75-95.25$ & 0.048 & $1.01 \%$ \\
\hline
\end{tabular}

The higher measurement uncertainty of the temperature level of the heating cartridge is negligible since it is only used as a security measurement to avoid the overheating of the heating cartridges. In order to achieve reproducible heating temperatures, the thermocouples in the upper level of pair 1 are monitored. Uncertainty in overall measurement results can be induced by the measurement equipment itself, as analyzed above, but also by uncertainties of the measurement procedure.

The first series of measurements consist of 54 operating points (Table 4 ), varying each the ambient pressure (atm, $\operatorname{vacuum}(\sim 30 \mathrm{mbar}))$, the traction force $\left(p_{c}\right)$ and the reference temperature at upper level of pair $1\left(T_{H}\right)$. All measurements are steady-state. During the measurement 60 data points were collected within a time period of five minutes and finally averaged. To analyze the impact of the ambient pressure on the heat transfer, the pressure in the surrounding atmosphere can be varied. Due to the variation of the contact pressure the effect of increasing rotational speed of the turbine rotor can be simulated and investigated. The variation of the heating temperature enables the simulation of a heating up procedure and to analyze heat radiation influence.

Table 4. Measurement schedule

\begin{tabular}{|l||r|}
\hline$p_{a m b}$ & atm, vacuum \\
\hline$T_{H}\left[{ }^{\circ} \mathrm{C}\right]$ & $150,250,350$ \\
\hline$p_{c}[k N]$ & $0.5,1.5,2.5,3.5,5.0,6.5,7.5,9.0,10.0$ \\
\hline
\end{tabular}

To prove the steady state measuring conditions, the temperature difference between thermocouple $\mathrm{T}_{4}$ and $\mathrm{T}_{5}$, as a parameter for the entering heat flux is provided in Fig. 9. This temperature difference fluctuates in a very narrow range up to $0.05 \mathrm{~K}$, which is within the band of measurement errors induced by the thermocouples. Hence, the time averaged measurement results can be assumed as steady-state.

\section{RESULTS \& DISCUSSION}

The first series of measurements, which is presented in this section, was conducted with a simplified blade specimen. To investigate the influence of the contact pressure isolated from other influences induced by the axial contact interfaces (CI1), these contact areas were removed. Consequently, the investigated blade specimen only has the radial contact interfaces (CI2).

For the evaluation of the measurement results, a dimensionless temperature is defined in Eq. 3. This temperature $\vartheta$ is the average temperature difference of the radial contact surfaces $\Delta \bar{T}_{C I 2}$, referenced on the temperature difference at the top and the bottom of the specimen (pair 1 - pair 7 ).

$$
\vartheta=\frac{\Delta \bar{T}_{C I 2}}{\bar{T}_{\text {Pair } 1}-\bar{T}_{\text {Pair } 7}}
$$

Figure 10 illustrates the measurement results as comparative temperature difference $\vartheta$ on the Y-Axis over the contact

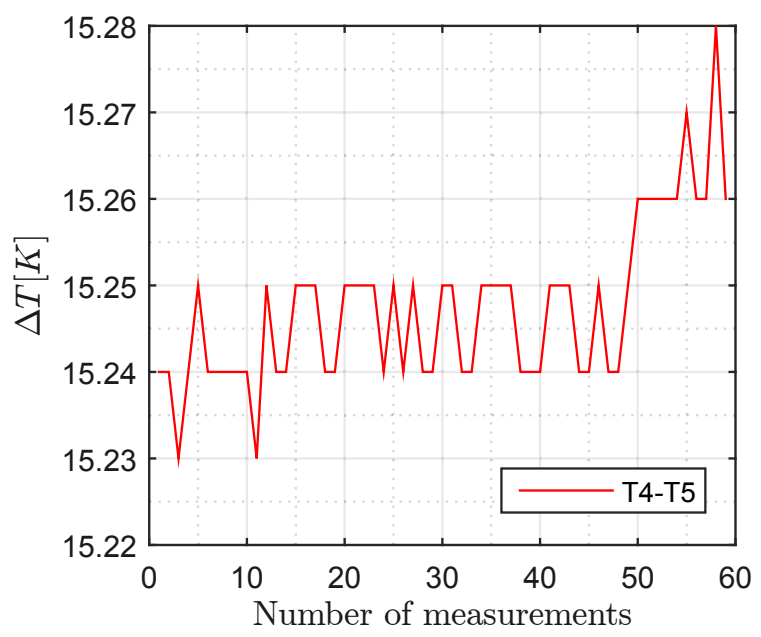

Figure 9. Temperature fluctuation over time between the measurement positions $\mathrm{T}_{4} \& \mathrm{~T}_{5}$ 
pressure $p_{c}$ at the contact interface $\mathrm{CI} 2$ respectively the equivalent rotational speed $n\left(n \propto p_{c}^{0.5}\right)$. The measurements with atmospheric ambient pressure are represented by a continuous line and that ones with evacuated atmosphere by a dot and dash line. The different temperature levels $\left(T_{H}\left[{ }^{\circ} \mathrm{C}\right]\right)$ are characterized by separate marker types and colors.

The expected global trend is a decrease in the contact temperature difference $\vartheta$ with increasing contact pressure. Both values of $\vartheta$ (atm \& vac) decrease with increasing temperature level, which indicates the heat radiation influence. At low contact pressure, the impact of the air pockets is significant as shown before in Fig. 8. This corresponds to the atmospheric results which show a clear temperature level dependency at low contact pressures due to conduction and heat radiation. The impact of the heat radiation increases with both, the temperature level and the temperature difference between the opposite surfaces. However, with increasing contact pressure, the air pockets lose impact due to the predominant effect of the metal conduction. At the highest measured contact pressure, the measurement results are very close.

In contrast to the very homogeneous trend of the atmospheric measurements, the results under an evacuated atmosphere show an increased scatter. It has been observed that the temperature distribution of the specimen is very sensitive on changes in the pressure level close to vacuum. During the measurements the pressure inside the pressure chamber has fluctuated around $3 \%$. The used vacuum pump is able to evacuate the pressure chamber on an absolute pressure level of 28 mbar, but without a regulation. This can be a reason for the inhomogeneous measurement results. However, the general trend of both, atmospheric and evacuated ambient pressure, is similar.

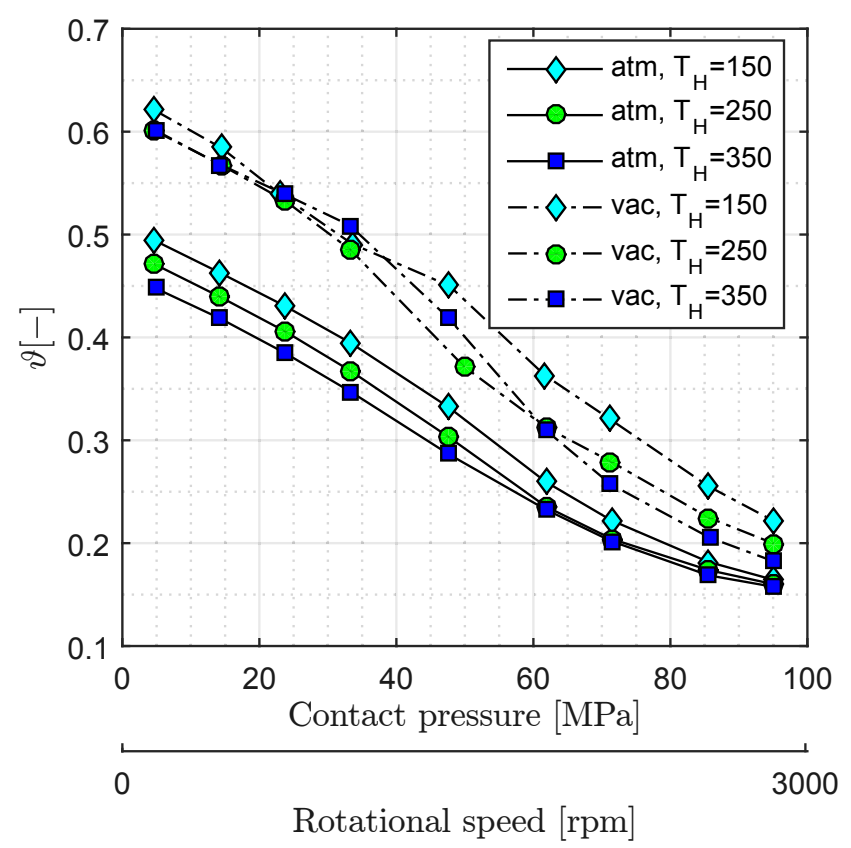

Figure 10. Average dimensionless temperature differences $\vartheta$ at contact interface $\mathrm{CI}_{2}$
At low contact pressure the difference of $\vartheta$ between the two pressure levels is high because of the high impact of the air pockets and thus, of the ambient pressure. Concerning an evacuated atmosphere it can be assumed that the heat transfer by conduction is negligible. Hence, the remaining heat transfer phenomenon is heat radiation.

Figure 11 shows the overall heat flux through the specimen depending on the contact pressure. The inlet heat flux, which is illustrated by a continuous line, is calculated by the temperature difference at pair 1 and the outlet heat flux (dot and dash line) is calculated by the temperature difference at pair 7 . Both of them are calculated with a temperature depending thermal conductivity. Atmospheric and evacuated ambient pressure measures can be differentiated by different line colors.

As a general trend it can be observed that the heat flux increases with increasing contact pressure and thus, with decreasing TCR. This effect is enhanced by the temperature level. The absolute heat losses - the difference between inlet and outlet - of the measurements with atmospheric pressure also increase with increasing temperature level. This effect can mainly be traced to the increasing heat flux, so that the relative heat losses are primary independent on the temperature level. This underlines the effect of the insulation surrounding the specimen. The heat losses at evacuated ambient pressure confirm this observation. The red lines in Fig. 11 are nearly matching, no matter the temperature level. At low contact pressure, the outlet heat flux is slightly above the inlet heat flux. This is within the range of measurement error.

\section{THERMAL CONTACT RESISTANCE}

For the determination of the thermal contact resistance the numerical FEM model as well as an one dimensional approach are developed.

A FEM model with integrated thermocouple holes and tetrahedral mesh (Fig. 12) is used for the numerical investi-

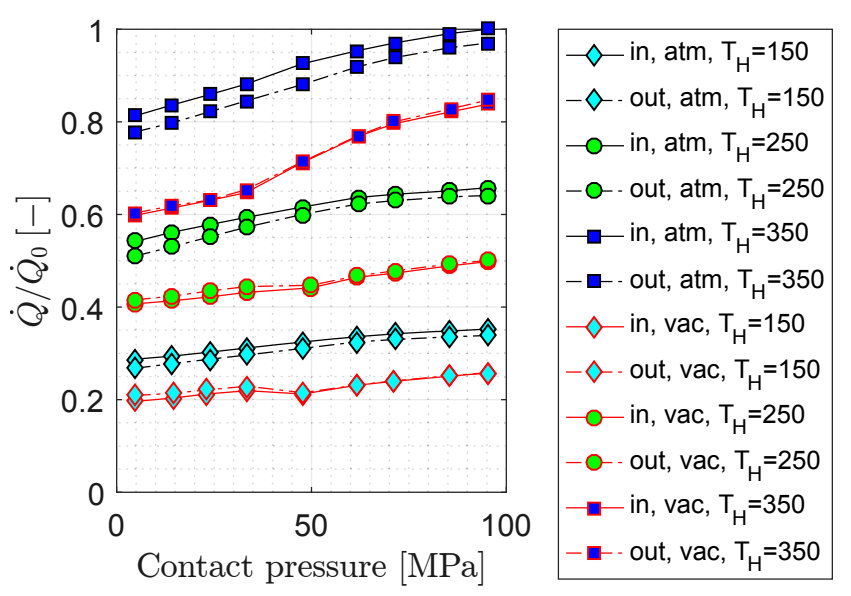

Figure 11. Incoming and outgoing heat fluxes for different measurement series 
gation. As boundary conditions, an average temperature of pair 1 is set at the upper and of pair 7 at the lower wall. All other surfaces except for the contact surfaces ( $\mathrm{CI} 2)$ and the surfaces of the air pockets are set adiabatically. Within the air pockets, the radiation heat flux and the conduction heat flux through the air is considered. At the contact surfaces, an initial TCR is defined. This TCR is adapted in an iterative process, in which the solver minimizes the error at the temperature measurement positions $\mathrm{T}_{9}, \mathrm{~T}_{11}, \mathrm{~T}_{14}$ and $\mathrm{T}_{15}$. These values are set based on the measurements. All other temperatures are calculated. A result is illustrated in Fig. 12 $\left(p_{c}=4.8 \mathrm{MPa}, \mathrm{vac}, T_{H}=150^{\circ} \mathrm{C}\right)$. It can be observed that the blade specimen has a clearly higher temperature than the rotor specimen. The traction force $F=4.8 \mathrm{MPa}$ is quite low. Thus, the TCR is high as well as the temperature difference between the contact surfaces.

The FEM model is able to recompute the temperature distribution in good accordance with the measurement data. The maximal deviation averaged for the measurement series is $2^{\circ} \mathrm{C}$.

For the examination of the TCR, also a simplified onedimensional (1D) approach is used and compared with the results of the FEM model (Fig. 13). The $1 \mathrm{D}$ model combined with a TCR correlation, which will be developed, enables the fast and simple calculation of the heat which is conducted from the blades to the rotor of a steam turbine. For the $1 \mathrm{D}$ approach it is assumed that the heat is transferred only in one dimension, orthogonally to the contact surface between

\section{$\mathrm{T} / \mathrm{T}_{0}[\mathrm{~K} / \mathrm{K}]$}

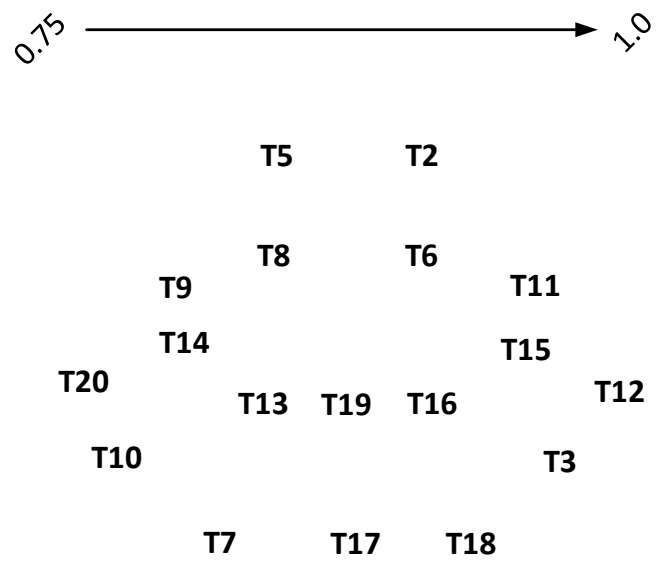

T23

T21

T22

Figure 12. Temperature distribution, calculated with FEM $\operatorname{model}\left(p_{c}=4.8 \mathrm{MPa}\right.$, vac, $\left.T_{H}=150^{\circ} \mathrm{C}\right)$ the opposite temperature measurement positions of the contact area CI2. For the calculation of the TCR, the averaged temperatures of the blade specimen $\left(\mathrm{T}_{13} \& \mathrm{~T}_{16}\right)$ and the rotor specimen ( $\left.\mathrm{T}_{14} \& \mathrm{~T}_{15}\right)$ as well as the temperature depending thermal conductivity and the entering heat flux at pair 1 are used. These calculation have been conducted for the series of measurements with evacuated atmosphere and $\bar{T}_{H}=150^{\circ} \mathrm{C}$, to assume negligible heat losses and negligible heat fluxes through the air pockets. The calculation results are shown in Fig. 13 compared with those calculated by the

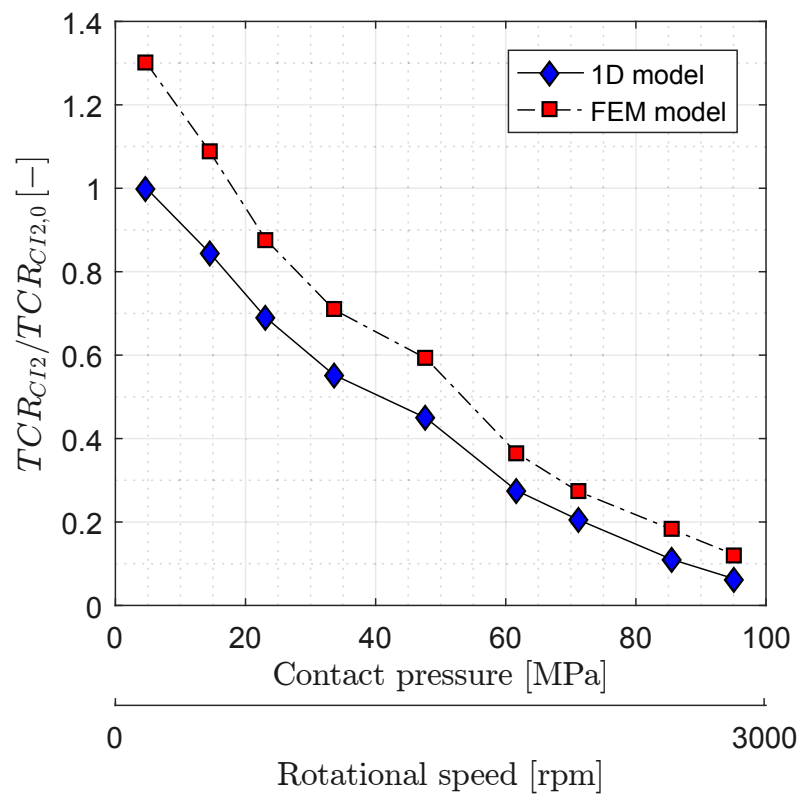

Figure 13. Comparison of thermal contact resistance (TCR) calculated by $1 \mathrm{D} \& \mathrm{FEM}$ model $\left(\mathrm{vac}, T_{H}=150^{\circ} \mathrm{C}\right)$

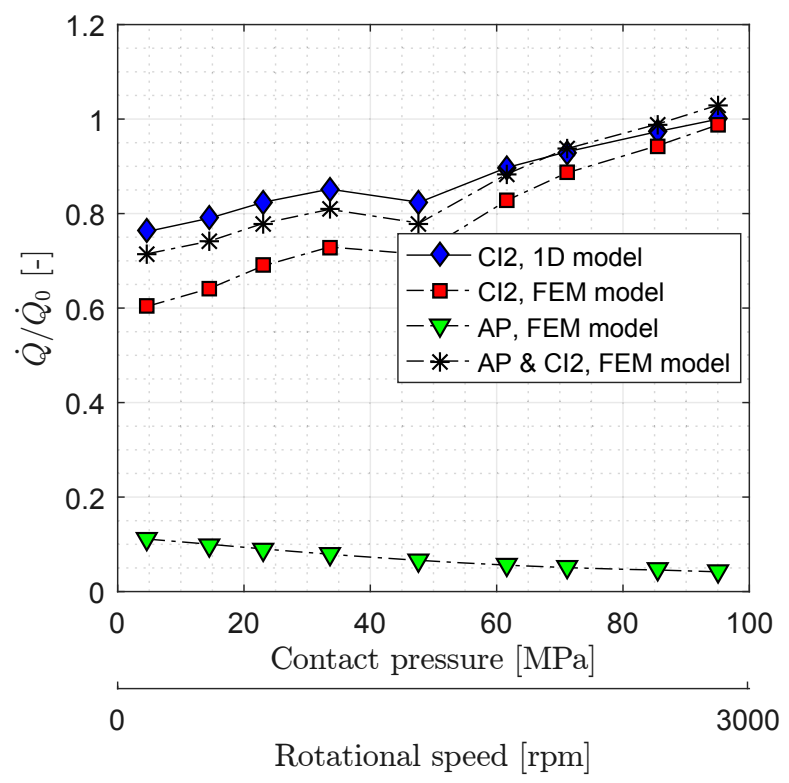

Figure 14. Comparison of heat fluxes calculated by $1 \mathrm{D} \&$ FEM model $\left(\operatorname{vac}, T_{H}=150^{\circ} \mathrm{C}\right)$ 
use of the numerical FEM model. It can bee seen that the TCR values of the numerical FEM model are higher than that one of the $1 \mathrm{D}$ approach. This deviation can be explained by the neglected heat fluxes through the air pockets by the $1 \mathrm{D}$ model. Both, the results of the FEM and the $1 \mathrm{D}$ model, are in the same range. The advantage of the $1 \mathrm{D}$ model is the very fast calculation time. Whereas, the CHT model has a higher accuracy.

Figure 14 shows the different heat fluxes through the air pockets (AP) and contact interfaces (CI) calculated with the FEM and $1 \mathrm{D}$ model. The results confirm the hypothesis that the deviation between $1 \mathrm{D}$ and CHT model is caused by the heat transfer through the air pockets. The transmitted share of radiation energy decreases with increasing contact pressure. Thus, the radiation influence decreases with decreasing TCR, which was predicted previously in Fig. 7 .

\section{CONCLUSION}

The present paper deals with an experimental set-up for applied investigations of the thermal contact resistance (TCR) at the blade-rotor-connection in a steam turbine. Therefore, a test rig was designed, which is able to measure the temperature at 26 different measurement positions within a rotor and blade specimen. The ambient pressure can be reduced for minimal heat losses and increased measurement accuracy. For the quantification of the measurement uncertainties, an uncertainty analysis has been conducted. The relative error of the relevant temperature measurements $\left(T_{1}-T_{26}\right)$ is less than $0.6 \%$.

First measurements with a specimen with radial contact interfaces were conducted and introduced. The results show a distinct trend with increasing contact pressure and increasing temperature level. For the determination of the TCR an ${ }_{1} \mathrm{D}$ approach as well as a numerical FEM model were developed. The results and a comparison of both models were presented. The TCR reaches high values with decreasing contact pressure. Thus, the assumption of full metal contact between the blade root and the rotor especial during operations with low rotational speed, such as start-up / cool-down or warm-keeping / pre-warming, is not justifiable.

In future investigations an analytical approach for the TCR will be developed based on the conducted and further measurements. Therefore, the influence of the contact surface properties (roughness and oxidation layer) will be analyzed. The final analytical correlation of the TCR will be integrated into a turbine model [cf. [15]] for simulating steam turbine warm-keeping operation.

\section{ACKNOWLEDGMENTS}

The authors gratefully acknowledge GE Power for their support and permission to publish this paper.

\section{REFERENCES}

[1] D. Toebben, P. Luczynski, M. Diefenthal, M. Wirsum, S. Reitschmidt, W. Mohr, and K. Helbig. Numerical in- vestigation of heat transfer and flow phenomena in an ip steam turbine in warm-keeping operation with hot air. Proceedings of ASME Turbo Expo, (GT2017-63555), 2017.

[2] D. Pusch, M. Voigt, K. Vogeler, P. Dumstorff, and H. Almstedt. Setup, validation and probalbilistic robustness estimation of a model for prediction of lcf in steam turbine rotors. ASME Turbo Expo, 2016.

[3] H. Fenech and W. M. Rohsenow. Prediction of thermal conductance of metallic surfaces in contact. Fournal of Heat Transfer, 1963.

[4] Borivoje B. Mikic and Warren M. Rohsenow. Thermal Contact Resistance. National Aeronautics and Space Administration, 1966.

[5] M. M. Yovanovich and H. Fenech. Thermal contact conductance of nominally flat rough surfaces in a vacuum evironment. Thermophysics and Temperature Control of Spacecraft and Entry Vehicles, 1966.

[6] M. G. Cooper, B. B. Mikic, and M. M. Yovanovich. Thermal contact conductance. International fournal of Heat and Mass Transfer, 1969.

[7] M. M. Yovanovich. Four decades of research on thermal contact, gap, and joint resistance in microelectronics. IEEE Transactions on Components and Packaging Technologies, 2005.

[8] Chakravarti V. Madhusudana. Thermal contact conductance. Mechanical Engineering Series. Springer, Cham, 2nd ed. edition, 2014.

[9] V.A. Ustinov, R. Kneer, F. Al-Sibai, S.G. Schulz, and E. ElMagd. Influence of surface roughness on contact heat transfer. Proceedings of the 14th International Heat Transfer Conference IHTC14, 2010.

[10] V. Ustinov, S. Schulz, R. Kneer, and E. El-Magd. Model development for the contact pressure dependent heat transfer. Motortechnische Zeitschrift : MTZ, 2011.

[11] E. M. Burghold, Y. Frekers, and R. Kneer. Determination of time-dependent thermal contact conductance through ir-thermography. International Journal of Thermal Sciences, 2015.

[12] J.D. Mar, E. Litovsky, and J. Kleiman. Modeling and database development of conductive and apparent thermal conductivity of moist insulation materials. Fournal of Building Physics Vol. 32, 2008.

[13] Evaluation of measurement data - guide to the expression of uncertainty in measurement. Technical report, Joint Committee for Guides in Metrology (JCGM), 2008.

[14] Iec 60584-1:2013: Thermocouples - part 1: Emf specifications and tolerance.

[15] D. Toebben, P. Luczynski, M. Wirsum, W. Mohr, and K. Helbig. Optimized approach for determination of the solid temperature in a steam turbine in warm-keepingoperation. ISROMAC, 2017. 